\title{
Improved antitumor efficacy of neutrophils stimulated by bacillus Calmette-Guérin
}

\author{
HUAN WANG $^{1,2}$, DANAN WANG $^{1}$, YONGHUI FENG ${ }^{1}$, JINGBO ZHAI $^{1}$ and CHANGLONG LU ${ }^{1}$ \\ ${ }^{1}$ Department of Immunology, School of Basic Medical Science, China Medical University, Shenyang, Liaoning 110122; \\ ${ }^{2}$ Pediatric Department, Shengjing Hospital of China Medical University, Shenyang, Liaoning 110022, P.R. China
}

Received April 9, 2018; Accepted May 31, 2019

DOI: $10.3892 / \mathrm{mmr} .2019 .10532$

\begin{abstract}
Bacillus Calmette-Guérin (BCG) has become a significant treatment for bladder cancer, and neutrophils are reported to be associated with the antitumor effect of BCG. The aim of the present study was to clarify the antitumor function of neutrophils stimulated by BCG. Initially, the killing effect and cytotoxic activity of neutrophils treated with BCG was detected. Subsequently, the effectiveness of BCG-treated neutrophils extracted from tumor-bearing mice was analyzed. The results revealed that the cytotoxic effect of neutrophils was stronger in the BCG-treated group compared with that in the normal saline (NS)-treated and control groups $(\mathrm{P}<0.05)$. A significantly higher concentration of cytokines tumor necrosis factor (TNF)- $\alpha$, interleukin (IL)-1 $\beta$, IL-6 and TNF-related apoptosis-inducing ligand occurred in the BCG-treated neutrophil group compared with the NS and control groups $(\mathrm{P}<0.01)$, which was also associated with the BCG dose $(\mathrm{P}<0.01)$. The gross tumor volume percentage in BCG-treated neutrophils from tumor-bearing mice (BCGT group) was significantly lower in comparison with that in the NS-treated neutrophils from tumor-bearing mice (NST group; $\mathrm{P}<0.05)$. In addition, the survival rate of tumor-bearing mice was higher in the BCGT group compared with the NST group $(\mathrm{P}<0.05)$, while more BCG-treated neutrophils from tumor-bearing mice were infiltrated in the MethA tumor $(\mathrm{P}<0.01)$. In conclusion, BCG-treated neutrophils were observed to enhance the antitumor efficacy and extend the life span of mice.
\end{abstract}

\section{Introduction}

Intravesical instillation of bacillus Calmette-Guérin (BCG) has become the golden standard for the treatment of superficial transitional cell carcinoma (TCC) of the bladder, and

Correspondence to: Dr Changlong Lu, Department of Immunology, School of Basic Medical Science, China Medical University, 77 Puhe Road, Shenyang, Liaoning 110122, P.R. China

E-mail: changlong_lu@sina.com

Key words: bacillus Calmette-Guérin, neutrophils, antitumor, cytokine activity has been successfully used for approximately four decades, significantly reducing mortality rates (1). Although the mechanism of BCG remains unclear, it is generally conceded that BCG instillation can induce multiple immunoreactions for tumor management and prevention (2). Cancer cells are first infected by BCG, which then induces the expression of various types of cytokines, such as tumor necrosis factor (TNF)- $\alpha$, interleukin (IL)-6 and IL-8, indicating an immunological response. Finally, the antitumor effect of BCG is performed by cytotoxic T lymphocytes, macrophages and natural killer cells. Neutrophils, which constitute the major cell subset in the leukocyturia detected after BCG instillation, or the TNF-related apoptosis-inducing ligand (TRAIL; also known as Apo-2L) protein produced by neutrophils have also been confirmed to be involved in the antitumor effect of BCG (3).

Neutrophils are the most abundant type of white blood cells, accounting for $40-70 \%$ of these cells. They are formed from stem cells in the bone marrow and are a crucial part of the innate immune system (4). Neutrophils are also one of the first responders of inflammation, particularly in bacterial infection, and are recruited within min. It has been reported that neutrophils can synthesize and secrete a small number of cytokines, including IL-1, IL-8, IL-12, TNF- $\alpha$, macrophage inflammatory protein 1 and transforming growth factor 1 , which may affect macrophage stimulation, neutrophil recruitment, and lymphocyte activation, proliferation and differentiation (5). Therefore, the function of neutrophils can be clarified by analyzing the expression profile of cytokines.

Although numerous studies have focused on BCG and neutrophils (6-8), the mechanism of neutrophil-mediated activation of tumor immunity remains unclear in the medical community. In the present study, in order to elucidate the antitumor effect of neutrophils stimulated by BCG, a tumor-bearing model was constructed in BALB/c mice, which was then subjected to BCG or normal saline (NS) intervention. The gross tumor volume (GTV), survival time and amount of neutrophils in the mice were examined.

\section{Materials and methods}

Ethical approval. The study was approved by the Ethics Committee of China Medical University (Shenyang, China), and all experiments were conducted according to the 
institutional guidelines for the care and use of laboratory animals (http://www.cmu.edu.cn/sydwb/index.htm).

Reagents and cell lines. Phosphate-buffered saline (PBS; $0.01 \mathrm{M}$ ) was sterilized by high-pressure steam for $15 \mathrm{~min}$ and stored at $4-8^{\circ} \mathrm{C}$, following preparation by dissolving $8 \mathrm{~g} \mathrm{NaCI}$, $0.2 \mathrm{~g} \mathrm{KCl}, 1.15 \mathrm{~g} \mathrm{Na}_{2} \mathrm{HPO}_{4}$ and $0.2 \mathrm{~g} \mathrm{KH}_{2} \mathrm{PO}_{4}$ in $900 \mathrm{mlddH}_{2} \mathrm{O}$ with $\mathrm{pH} 7.4$ and bringing the whole volume to $1,000 \mathrm{ml}$ with $\mathrm{ddH}_{2} \mathrm{O}$. The $\mathrm{BCG}$ solution $\left[10 \mathrm{mg} / \mathrm{ml} ; 10^{8}\right.$ colony-forming units $(\mathrm{CFU}) / \mathrm{ml}$ ] was obtained by dissolving $1 \mathrm{~g}$ BCG powder (Shanghai Research Institute of Biological Products) in $100 \mathrm{ml} \mathrm{NS}$, and was then further attenuated to $10^{7}, 10^{6}$ and $10^{5} \mathrm{CFU} / \mathrm{ml}$ solutions. Oyster glycogen solution (2\%) was prepared by adding 2 g oyster glycogen (Sigma-Aldrich; Merck KGaA) to $100 \mathrm{ml} \mathrm{NS}$, followed by attenuation to $0.25,0.5,1$ and $1.5 \%$ solutions, filtration and sterilization. Fetal calf serum FCS)-RPMI-1640 medium was prepared

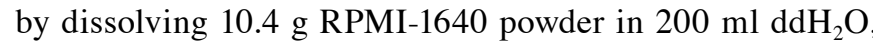
and adding $2 \mathrm{~g} \mathrm{NaHCO}_{3}$ and $100 \mathrm{ml} \mathrm{FCS}$, and the medium was then stored at $4-8^{\circ} \mathrm{C}$. Mouse neutrophil separation solution was purchased from Tianjin Haoyang Biological Manufacture Co., Ltd., and the ELISA kits were from Thermo Fisher Scientific, Inc. The instruments used included a centrifuge (Jouan CR411; Thermo Fisher Scientific, Inc.), optical microscope (Olympus Corporation), $-80^{\circ} \mathrm{C}$ freezer (Kelvinator; Electrolux) and an analytical balance (L-1660 DTP; Shimadzu Corporation).

MethA fibrosarcoma cells were obtained from the Hirosaki University of Medicine (Hirosaki, Japan), while yeast artificial chromosome-1 (YAC-1) cells were obtained from the China Medical University (Shenyang, China). Cells were maintained in RPMI-1640 culture medium at $37^{\circ} \mathrm{C}$ in $5 \% \mathrm{CO}_{2}$ for $24-48 \mathrm{~h}$ and modified to a concentration of $1 \times 10^{5} / \mathrm{ml}$.

Animals. Female BALB/c mice (age, 6-8 weeks; weight, 18-22 g) were obtained from the Chinese Academy of Sciences (Shanghai, China). The mice were kept in plastic cages $\left(23 \pm 2^{\circ} \mathrm{C}\right.$ and $55.5 \pm 10 \%$ relative humidity) with free access to water and food and exposed to a $12 \mathrm{~h}$ fluorescent light/dark cycle for a week before experiments.

Extraction of neutrophils. BALB/c mice were subcutaneously injected with $0.1 \mathrm{ml} \mathrm{BCG}$ of $10^{6} \mathrm{CFU} / \mathrm{ml}$ (BCG group) or with NS (NS group) according to previously described experiments on detecting the effect of BCG $(6,7)$. A third group without any intervention was selected as the control. At $4 \mathrm{~h}$ after intraperitoneal injection with $1.5 \mathrm{ml}$ oyster glycogen solution (1\%), the mice were euthanized and their enterocoelia were lavaged with 7-8 $\mathrm{ml}$ sterile PBS, and then peritoneal cells were extracted by centrifugation at $1,000 \mathrm{x}$ g for $5 \mathrm{~min}$ at room temperature. The supernatant was discarded and cells were resuspended with $1 \mathrm{ml}$ RPMI-1640 medium. Next, the resuspended cell solution was transferred to the top of the mouse neutrophil separation liquid $(2 \mathrm{ml})$ in a $15-\mathrm{ml}$ tube, and centrifugation was again performed at $1,000 \mathrm{x} \mathrm{g}$ at $23^{\circ} \mathrm{C}$ for $5 \mathrm{~min}$. The liquid at the top of the neutrophil cellular layer was subsequently discarded, and $4 \mathrm{ml}$ sterile PBS was added to the remaining solution and further centrifuged $\left(1,000 \times \mathrm{g}, 23^{\circ} \mathrm{C}, 5 \mathrm{~min}\right)$. Finally, the neutrophils were rinsed twice and resuspended with $1 \mathrm{ml}$ RPMI-1640 medium.
Construction of a tumor-bearing mouse model. The abdominal cavity of BALB/c mouse was injected with $1 \times 10^{6} / \mathrm{ml}$ MethA cells and lavaged with 2-3 ml sterile PBS after 5 days. Next, ascitic fluid was collected and centrifuged $(1,000 \mathrm{x} \mathrm{g}$, room temperature, $5 \mathrm{~min}$ ). The supernatant was discarded, and cells were resuspended with $5 \mathrm{ml}$ sterile PBS and centrifuged (1,000 x g, room temperature, $5 \mathrm{~min})$. Subsequently, the supernatant was once more discarded, and $1 \mathrm{ml} \mathrm{NS}$ was added to suspend the cells, which were then modified to a concentration of $1 \times 10^{7} / \mathrm{ml}$. Finally, $0.1 \mathrm{ml}$ MethA suspended cells were hypodermically injected into the right posterior limb of the mice. After 1 week, a mass could be observed, indicating the accomplishment of tumor-bearing mouse models, which were divided into group A and group B.

Next, BCG $\left(0.1 \mathrm{ml} ; 10^{6} \mathrm{CFU} / \mathrm{ml}\right)$ or NS was injected into group A tumor-bearing mice once every 2 days for 6 days. Neutrophils were extracted from these mice on the second day of the third injection. Subsequent to rinsed for two times, neutrophils were resuspended with $1 \mathrm{ml} \mathrm{NS}$ and then modified to a concentration of $1 \times 10^{7} / \mathrm{ml}$. Then, group B tumor bearing mice $(n=15)$ were subcutaneously injected with these neutrophils extracted from group A tumor-bearing mice treated by BCG or NS, which were titled as BCGT and NST groups. The rest mice injected with the neutrophils from untreated group A tumor-bearing mice were assigned to CT group.

Assessment of cytokine activity. Cytokine activity was assessed by lactate dehydrogenase (LDH) Cytotoxicity Assay Kit (Beyotime Institute of Biotechnology) according to the manufacturer's protocol. Neutrophils from the three groups (namely BCG, NS and control groups) were modified to obtain a concentration of $5 \times 10^{6} / \mathrm{ml}$ using RPMI-1640 medium supplemented with $10 \%$ FCS (Biochrom). Next, $0.1 \mathrm{ml}$ MethA and YAC-1 cells were individually placed in a 96-well plate with a 50:1 effector target ratio. Each group was plated in triplicate. Subsequent to culturing at $37^{\circ} \mathrm{C}$ for $3 \mathrm{~h}, 0.1 \mathrm{ml}$ supernatant taken from each well was reacted with $0.1 \mathrm{ml} \mathrm{LDH}$ substrate, and $30 \mu 11 \mathrm{~mol} / 1$ citric acid solution was added to terminate the enzymatic reaction after $20 \mathrm{~min}$. Absorbance of each samples was measured at $490 \mathrm{~nm}$ test wavelength and at $630 \mathrm{~nm}$ reference wavelength by a microplate reader (Bio-Rad Laboratories, Inc.). The percentage of cell death was calculated using the following formula: cytotoxicity $(\%)=($ experimental value-low control $) /($ high control-low control) x $100 \%$.

In addition, neutrophils extracted from BCG-treated and NS-treated mice were modified to obtain a concentration of $2 \times 10^{6} / \mathrm{ml}$ using RPMI-1640 medium supplemented with $10 \% \mathrm{FCS}$, and cultured for $6 \mathrm{~h}$. Next, the supernatant was collected following centrifugation at $1,000 \mathrm{x} \mathrm{g}$ for $10 \mathrm{~min}$ at room temperature. According to the ELISA (Thermo Fisher Scientific, Inc.) protocol, the densities $(\mathrm{pg} / \mathrm{ml})$ of the cytokines TNF- $\alpha$ (BMS607-3), IL-1 $\beta$ (BMS6002), IL-6 (BMS603-2) and TRAIL/Apo-2L (EMTNFSF10) were calculated.

Furthermore, neutrophils extracted from untreated mice were modified to a concentration of $2 \times 10^{6} / \mathrm{ml}$, and treated with NS or BCG at different concentrations $(0.01,0.1$ and $1 \mathrm{mg} / \mathrm{ml}$ BCG in groups 1,2 and 3, respectively). Cells were cultured for $6 \mathrm{~h}$, and then the densities (pg/ml) of TNF- $\alpha$, IL-1 $\beta$, IL- 6 and TRAIL/Apo-2L were assessed. 
Survival rate and GTV of tumor-bearing mice. Subsequent to neutrophil injection, the mortality of mice was recorded every day for a total of 18 days, and the survival rate was calculated using the Graph Pad Prism 5 software (GraphPad Software, Inc.). In addition, the long and short radius (mm) of the tumor was assessed every 2 days, and the GTV was calculated according to the following formula: GTV $=($ Long radius $\mathrm{x}$ short $\left.\operatorname{radius}^{2}\right) / 2$.

Pathological examination of MethA tumor. At $24 \mathrm{~h}$ after neutrophil injection, the mice were sacrificed and stabilized in the prone position. Tumors were extracted, fixed in $6 \%$ buffered formalin, routinely processed with paraffin, stained by hematoxylin and eosin and finally mounted with neutral resins. An optical microscope was employed to calculate the amount of neutrophils in 10 fields-of-view.

Statistical analysis. Statistical analysis was performed by SPSS software, version 11.5 (SPSS, Inc.). Analysis of variance and Dunnett's multiple comparisons test were used to test for significant differences between the mean values. Differences were considered to be statistically significant at $\mathrm{P} \leq 0.05$.

\section{Results}

Cytotoxic activity of BCG-treated neutrophils. As shown in Fig. 1 , BCG-treated $\left(0.1 \mathrm{mg} / \mathrm{ml}, 10^{6} \mathrm{CFU} / \mathrm{ml}\right)$ neutrophils presented higher percentage of cytotoxicity in both MethA and YAC-1 tumor cells compared with the NS group $(\mathrm{P}<0.05)$ and the control group without any intervention $(\mathrm{P}<0.05)$. This indicated that BCG can enhance the cytotoxic activity of neutrophils in defeating tumor cells.

Concentration of cytokines in BCG-treated neutrophils. In order to clarify the possible mechanism involved in the effect of BCG on neutrophils, the concentration of cytokines in neutrophil supernatant extracted from treated mice was detected. It was observed that the concentration of the cytokines TNF- $\alpha$, IL-1 $\beta$, IL-6 and TRAIL/Apo-2L was significantly higher in the BCG group $\left(0.1 \mathrm{mg} / \mathrm{ml}, 10^{6} \mathrm{CFU} / \mathrm{ml}\right)$ as compared with the control $(\mathrm{P}<0.01)$ and NS groups $(\mathrm{P}<0.05)$. This indicated that BCG-treated neutrophils can induce cytokines to kill tumor cells (Fig. 2).

Concentration of cytokines in neutrophils treated with different doses of $B C G$. Further experiments were conducted to determine whether different concentrations of BCG could affect the results. As shown in Fig. 3, the concentration of abovementioned cytokines remained high in all three BCG groups tested $\left(0.01,0.1\right.$ and $\left.1 \mathrm{mg} / \mathrm{ml}, 10^{6} \mathrm{CFU} / \mathrm{ml}\right)$ compared with the control and NS groups $(\mathrm{P}<0.01)$. Higher doses of $\mathrm{BCG}$ led to increased concentration of cytokines, suggesting that BCG at higher doses may lead to an improved antitumor effect.

Survival rate of tumor-bearing mice. In order to examine the anticancer effectiveness of BCG-treated neutrophils, group A tumor-bearing model was initially constructed and treated with BCG or NS. Next, neutrophils were extracted from these tumor-bearing mice and injected into group B tumor-bearing mice. Finally, the results obtained in the CT, NST and

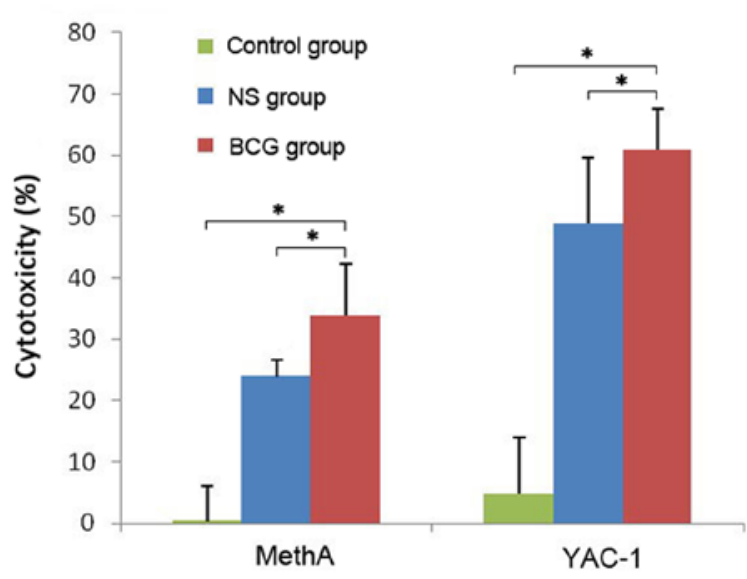

Figure 1. Cytotoxicity of BCG-treated neutrophils. Tumor cells MethA and YAC-1 were intervened by the neutrophils treated with or without BCG $\left(10^{6} \mathrm{CFU} / \mathrm{ml}\right)$ or NS. BCG group presented significantly higher percentage of cytotoxicity compared with the NS and control group. ${ }^{*} \mathrm{P}<0.05$. BCG, bacillus Calmette-Guérin; NS, normal saline.

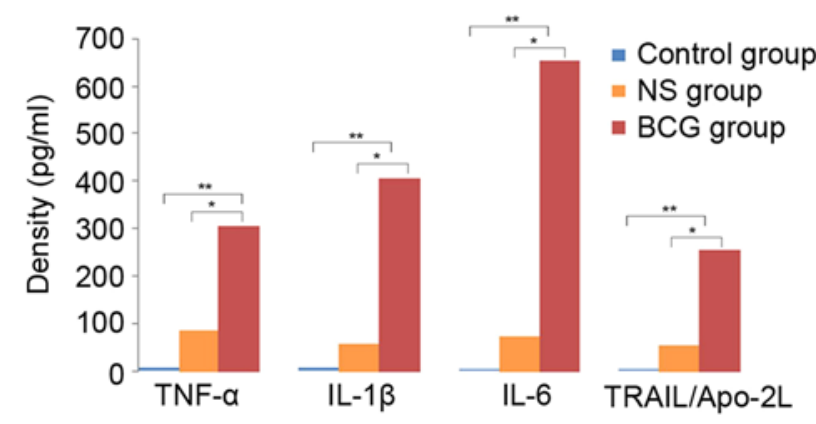

Figure 2. Concentration of cytokines in BCG $\left(10^{6} \mathrm{CFU} / \mathrm{ml}\right)$-treated neutrophils. A higher concentration of cytokines TNF- $\alpha$, IL-1 $\beta$, IL- 6 and TRAIL/Apo-2L can be observed in the BCG group as compared with the control and NS groups. ${ }^{*} \mathrm{P}<0.05$ and ${ }^{* *} \mathrm{P}<0.01$. BCG, bacillus Calmette-Guérin; NS, normal saline; TNF- $\alpha$, tumor necrosis factor- $\alpha$; IL, interleukin; TRAIL, TNF-related apoptosis-inducing ligand.

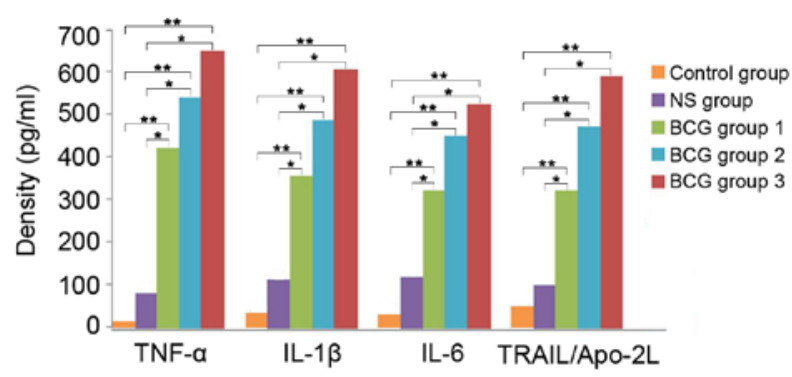

Figure 3. Concentration of cytokines in neutrophils treated with different doses of BCG. Higher concentration of cytokines TNF- $\alpha$, IL-1 $\beta$, IL- 6 and TRAIL/Apo-2L was observed in the three BCG-treated groups as compared with the NS and control groups, and the effect was dose-dependent. ${ }^{*} \mathrm{P}<0.05$ and ${ }^{* *} \mathrm{P}<0.01$. BCG, bacillus Calmette-Guérin; NS, normal saline; TNF- $\alpha$, tumor necrosis factor- $\alpha$; IL, interleukin; TRAIL, TNF-related apoptosis-inducing ligand.

BCGT groups were compared. At 1 week after MethA cell inoculation, a phyma was observed, indicating the successful establishment of the tumor-bearing model. As shown in Fig. 4, a decline in the survival rate was observed on day 12 in the 


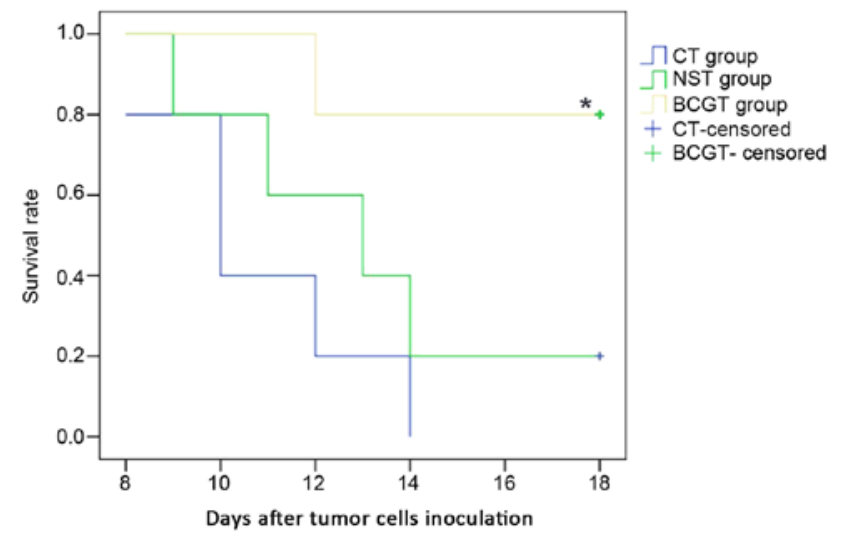

Figure 4. Survival rate of tumor-bearing mice. A decline in the survival rate began on day 12 in the BCGT group $\left(10^{6} \mathrm{CFU} / \mathrm{ml}\right)$, on day 9 in the NST group, and on day 10 in the CT group. On day 18, the survival rates in the three groups were 80,20 and $0 \%$, respectively. The survival rate in the BCGT group was higher as compared with that in the NST and CT groups. ${ }^{*} \mathrm{P}<0.05$ vs. CT and NST groups. A cross signifies the final day of observation. BCG, bacillus Calmette-Guérin; NS, normal saline; BCGT, intervention with BCG-treated neutrophils from tumor-bearing mice; NST, intervention with NS-treated neutrophils from tumor-bearing mice; CT, intervention with untreated neutrophils from tumor-bearing mice.

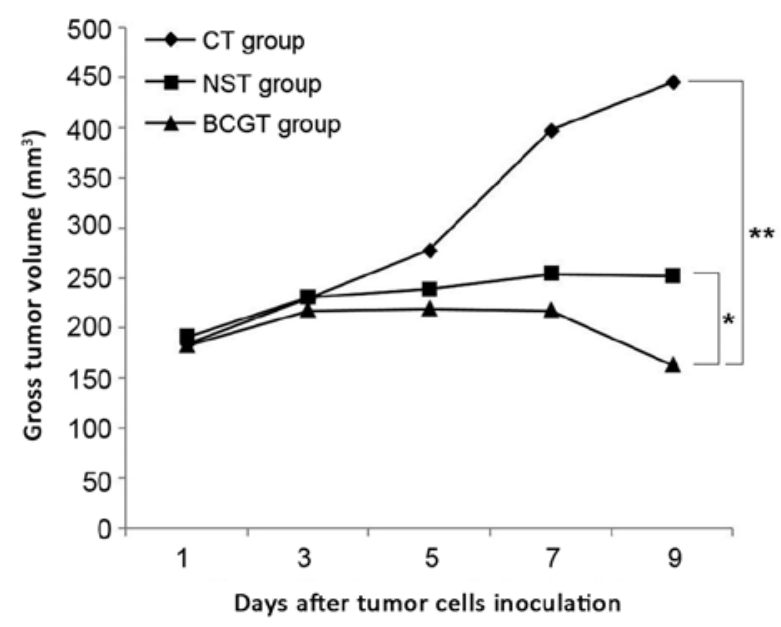

Figure 5. GTV in mice intervened with or without BCG $\left(10^{7} \mathrm{CFU} / \mathrm{ml}\right)$ or NS. At 7 days after neutrophil injection, the percentage of GTV in the BCGT group was significantly lower compared with that in the NST and CT groups. The GTV percentage in the BCGT group decreased on day 9 . $^{*} \mathrm{P}<0.05$ and ${ }^{* *} \mathrm{P}<0.01$. GTV, gross tumor volume; BCG, bacillus Calmette-Guérin; NS, normal saline. BCGT, intervention with BCG-treated neutrophils from tumor-bearing mice; NST, intervention with NS-treated neutrophils from tumor-bearing mice; CT, intervention with untreated neutrophils from tumor-bearing mice.

BCGT group, on day 9 in the NST group and on day 10 in the CT group. On day 18 , the survival rate in the three groups was 80,20 and $0 \%$, respectively. The survival rate in the BCGT group was significantly higher compared with the NST and CT groups (both $\mathrm{P}<0.05$; Fig. 4).

GTV. At 7 days after neutrophil injection, the GTV in the BCGT group was significantly lower in comparison with that in the NST and CT groups (both $\mathrm{P}<0.05$ ). Furthermore, the GTV exhibited a tendency to decrease only in the BCGT group on day 9 , indicating that BCG enhanced the effect of neutrophils and further decreased the tumor volume (Fig. 5).
Pathological examination of MethA tumor in mice. The tumor-bearing mice were sacrificed and stabilized in the prone position subsequent to neutrophil injection for $24 \mathrm{~h}$. After evaluation under an optical microscope, enhanced neutrophil infiltration was observed in the BCGT group compared with the NST and CT groups (both $\mathrm{P}<0.01$; Figs. 6 and 7). In addition, a consistent amount of neutrophils was detected in 10 fields-of-view.

\section{Discussion}

In the present study, two experiments were performed: Initially, the cytokine activity of BCG-treated neutrophils was evaluated, and it was observed that BCG enhanced the antitumor effect of neutrophils by inducing cytokine expression. Subsequently, a tumor-bearing mouse model was constructed, and the results suggested that the group injected with BCG-treated neutrophils extracted from tumor-bearing mice exhibited increased neutrophil infiltration with significantly decreased tumor GTV percentage and elevated survival rate. Overall, the results demonstrated that BCG-treated neutrophils were effective in reducing tumor growth and extending the life span of mice due to their enhanced cytotoxic activity.

In recent years, neutrophils have received attention since they are believed to serve an important role in BCG therapy. Neutrophils are the most abundant among all white blood cells in the circulatory system of humans, and these cells can recognize and induce tumor cell death through cytotoxicity. SR/CR mice are known to be capable of killing tumor cells through their innate immune system and neutrophils serve an important role in this process. Based on cell phenotype detection, it is observed that the cytotoxicity of neutrophils on tumor cells was $38 \%$, compared with 35 and $26 \%$ in natural killer cells and macrophages respectively $(9,10)$. A previous study suggested that, along with the increasing expression levels of various cytokines, a great number of neutrophils and monocytes were infiltrated in the bladder wall (11). Furthermore, Suttmann et al (12) reported that tumor-bearing mice intervened with BCG exhibited an increasing neutrophil infiltration. The study also indicated that the therapeutic effect of BCG would disappear and the survival rate would decrease to the level of untreated control mice if neutrophils were depleted, indicating that BCG treatment would become invalid in mice with a lack of neutrophils. It is also reported that certain cytokines were detected following the first BCG instillation, demonstrating that neutrophils can induce cytokines to inhibit tumor cells $(13,14)$.

In the present study, we attempted to identify the mechanism of BCG-treated neutrophils in defeating tumors by detecting the activities of cytokines TNF- $\alpha$, IL-1 $\beta$, IL- 6 and TRAIL/Apo-2L in BCG-treated neutrophil supernatant. In the experiments, MethA and YAC-1 cell lines were adopted, since the former cells are frequently used for the evaluation of the antitumor activity of different agents $(15,16)$, and the later cells are typically used as target cells for the determination of the cytotoxic activity of natural killer cells in mice (17). Besides, MethA and YAC-1 cells are commonly used in our lab to detect the antitumor effect of various agents.

TNF- $\alpha$ is postulated to be a cell signaling protein with high killing effect on tumor cells, which can be induced by 

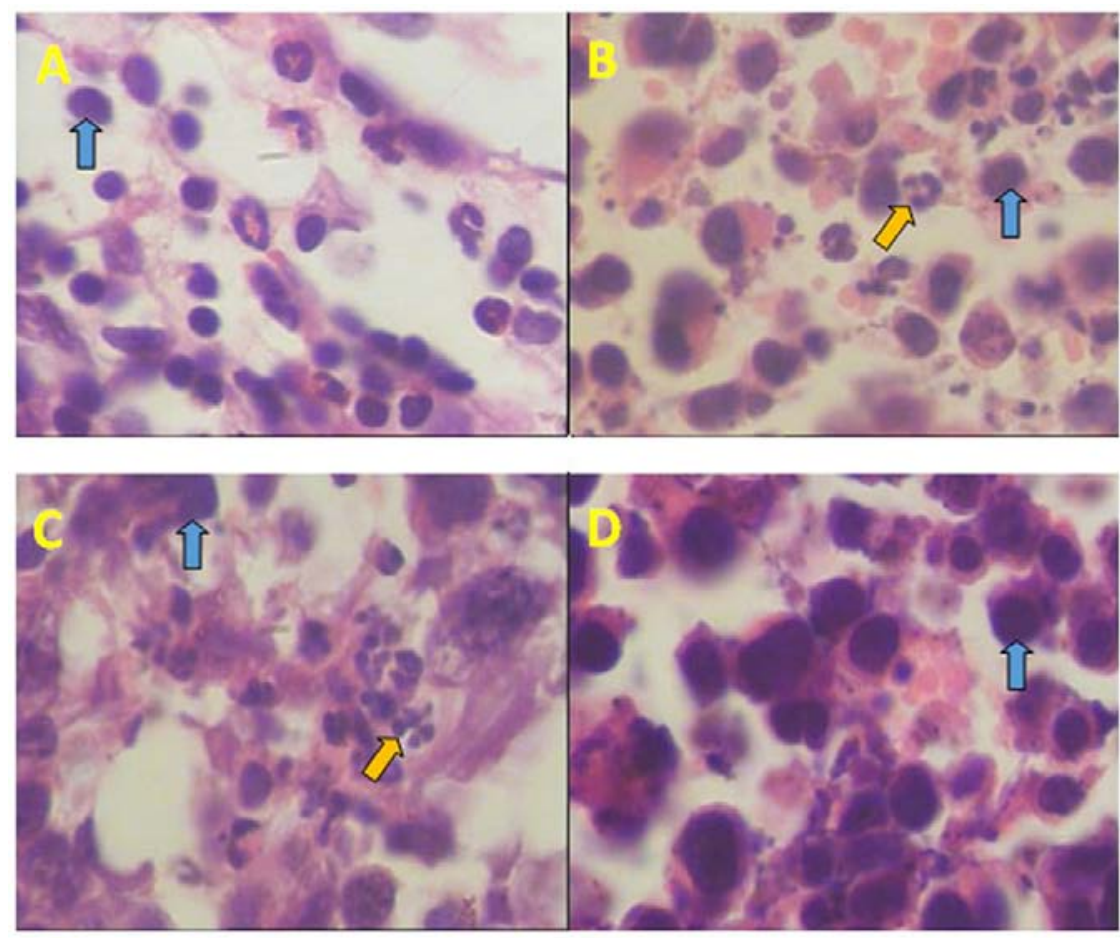

『 Neutrophils $\Uparrow$ Tumor cells

Figure 6. Hematoxylin and eosin staining of MethA tumor tissue (magnification, x1,000). MethA tumor intervened with (A) NS-treated neutrophils, (B and C) BCG-treated neutrophils $\left(10^{6} \mathrm{CFU} / \mathrm{ml}\right)$, and (D) untreated neutrophils. Increased neutrophil infiltration occurred in the BCGT group compared with the NST and CT groups. Yellow arrows indicate neutrophils and blue arrows indicate tumor cells. BCG, bacillus Calmette-Guérin; NS, normal saline. BCGT, intervention with BCG-treated neutrophils from tumor-bearing mice; NST, intervention with NS-treated neutrophils from tumor-bearing mice; CT, intervention with untreated neutrophils from tumor-bearing mice.

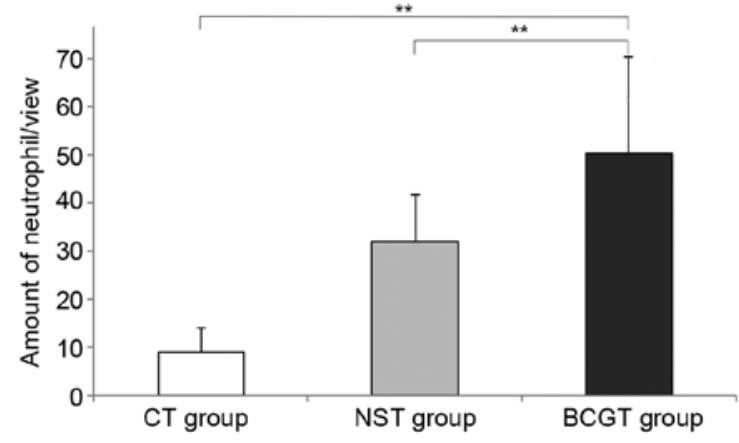

Figure 7. Amount of neutrophils infiltrated in the MethA tumor, calculated in 10 fields-of-view. The amount of neutrophils in the BCGT group $\left(10^{7} \mathrm{CFU} / \mathrm{ml}\right)$ was higher compared with that in the NST and CT groups. ${ }^{* * *} \mathrm{P}<0.01$. BCG, bacillus Calmette-Guérin; NS, normal saline. BCGT, intervention with BCG-treated neutrophils from tumor-bearing mice; NST, intervention with NS-treated neutrophils from tumor-bearing mice; $\mathrm{CT}$, intervention with untreated neutrophils from tumor-bearing mice.

activated neutrophils (18). In a recent study, Bisiaux et al (19) reported the secretion of TNF- $\alpha$ following BCG stimulation. IL-1 $\beta$ is an important mediator of inflammatory response produced by activated macrophages, which is also involved in a variety of cellular activities, including cell proliferation, differentiation and apoptosis (20). IL-6, a cytokine with multiple functions, is regarded as a pro-inflammatory cytokine and anti-inflammatory myokine, and is secreted by $\mathrm{T}$ cells and macrophages. In addition, TRAIL/Apo-2L, a type 2 membrane protein and a member of the TNF superfamily, is produced by activated T cells $(21,22)$, B cells (23), natural killer cells (24), dendritic cells (25) and monocytes (26). It is reported that TRAIL/Apo-2L released from neutrophils is a crucial step in anticancer therapy using BCG (27). It has also been reported that patients treated with BCG had higher TRAIL/Apo-2L urinary levels, which can induce apoptosis in bladder tumor cells (28). Therefore, the abovementioned cytokines can serve as the endpoints for detecting the antitumor effect of neutrophils stimulated by BCG. In the current study, BCG-treated neutrophils were found to be effective in killing MethA and YAC-1 cells, as well as inducing a significantly larger number of cytokines compared with those in the control and NS groups, which is consistent with the findings of the aforementioned studies.

Furthermore, the experiments of the present study revealed that the efficacy of neutrophils was largely dependent on the dose of BCG. Previous bladder cancer research conceded that, on account of the innate defense mechanism of the bladder, higher doses may lead to better outcomes, since the glycosaminoglycans on the surface of the urothelium are negatively charged to protect the bladder urothelium bacteria, such as BCG, whose surfaces are highly negatively charged; thus, a high dose of BCG is required for intravesical therapy (2).

Additionally, it was observed that the neutrophils from BCG-treated tumor-bearing mice presented a surprising effectiveness compared with those in the NS group, with the difference reaching statistical significance. However, there has been no study, to the best of the authors' knowledge, which analyzes the antitumor effect of neutrophils from the 
BCG-treated tumor-bearing mice, which is considered to be one of the most important findings of the present study.

Since first adopted by Morales in 1976 (29), BCG has become a standard treatment for non-muscle-invasive bladder cancer, and has been demonstrated to be effective and superior to chemotherapy. Bladder cancer is also one of the immunogenic types of cancer, capable to escape from immune-mediated elimination even in the presence of antigen-specific immune cell infiltration (30). Therefore, BCG is suggested to function by inducing inflammatory response to activate the immune reaction. Nevertheless, there is no consensus on the mechanism underlying the anticancer effect of BCG. Kawai et al (2) suggested an immunotherapy model for BCG in a previous review. These authors suggested that instillation of BCG into the bladder leads to the attachment of BCG to tumor cells through fibronectin mediation, which is regarded as the first step of immune response stimulated by BCG. Next, BCG internalization induces an immunological response characterized by cytokine accumulation, and macrophage and lymphocyte recruitment into the bladder wall to defeat tumors.

However, since we were unable to access bladder tumor cells, this study only evaluated the antitumor effect of BCG-treated neutrophils, which may be the possible mechanism of BCG-treated neutrophils in bladder cancer. Besides, neutrophils have conflicting functions: on one hand, they can defeat tumor cells; on the other, they can also lead to redundant inflammation and induce factors for malignant cells and matrix-degrading enzyme secretion (31), which prevent the development of long-lasting immunity (7) and promote cancer under long-term influence (12). Therefore, future research focused on bladder cancer is required.

In conclusion, ex vivo and in vivo experiments on mice were performed in the present study to demonstrate that BCG-treated neutrophils were effective in killing tumor cells and extending the life span of mice by stimulating cytotoxic activity.

\section{Acknowledgements}

Not applicable.

\section{Funding}

This study was financially supported by grants from the National Natural Science Foundation of China (no. 31270972) and the Shenyang Science and Technology Project 'Anti-tumor effect of neutrophils induced by BCG' in 2009 (no. 1091175-1-02).

\section{Availability of data and materials}

The datasets used during the current study are available from the corresponding author on reasonable request.

\section{Authors' contributions}

HW developed concept and design of the study; DW, YF, HW and CL performed the experiments; JZ collected and analyzed data; HW and YF interpreted data; CL drafted and revised the manuscript. All authors read and approved the final manuscript.

\section{Ethics approval and consent to participate}

The study was approved by the Ethics Committee of China Medical University (Shenyang, China).

\section{Patient consent for publication}

Not applicable.

\section{Competing interests}

The authors declare that they have are no competing interests.

\section{References}

1. Spencer BA, McBride RB, Hershman DL, Buono D, Herr HW, Benson MC, Guptamohile S and Neugut AI: Adjuvant intravesical bacillus calmette-guérin therapy and survival among elderly patients with non-muscle-invasive bladder cancer. J Oncol Pract 9: 92-98, 2013.

2. Kawai K, Miyazaki J, Joraku A, Nishiyama $\mathrm{H}$ and Akaza $\mathrm{H}$ : Bacillus Calmette-Guerin (BCG) immunotherapy for bladder cancer: Current understanding and perspectives on engineered BCG vaccine. Cancer Sci 104: 22-27, 2013.

3. Saint F, Patard JJ, Irani J, Salomon L, Hoznek A, Legrand P, Debois H, Abbou CC and Chopin DK: Leukocyturia as a predictor of tolerance and efficacy of intravesical BCG maintenance therapy for superficial bladder cancer. Urology 57: 617-622, 2001.

4. Ermert D, Niemiec MJ, Röhm M, Glenthøj A, Borregaard N and Urban CF: Candida albicans escapes from mouse neutrophils. J Leukoc Biol 94: 223-236, 2013.

5. Koga Y, Matsuzaki A, Suminoe A, Hattori H and Hara T: Neutrophil-derived TNF-related apoptosis-inducing ligand (TRAIL): A novel mechanism of antitumor effect by neutrophils. Cancer Res 64: 1037-1043, 2004.

6. Antony VB, Sahn SA, Antony AC and Repine JE: Bacillus Calmette-Guérin-stimulated neutrophils release chemotaxins for monocytes in rabbit pleural spaces and in vitro. J Clin Invest 76: 1514-1521, 1985.

7. Moliva JI, Turner J and Torrelles JB: Immune responses to bacillus Calmette-Guérin vaccination: Why do they fail to protect against Mycobacterium tuberculosis? Front Immunol 8: 407, 2017.

8. Rosevear HM, Lightfoot AJ, O'Donnell MA and Griffith TS: The role of neutrophils and TNF-related apoptosis-inducing ligand (TRAIL) in bacillus Calmette-Guérin (BCG) immunotherapy for urothelial carcinoma of the bladder. Cancer Metastasis Rev 28: 345-353, 2009.

9. Hicks AM, Riedlinger G, Willingham MC, Alexander-Miller MA, Von Kap-Herr C, Pettenati MJ, Sanders AM, Weir HM, Du W, Kim J, et al: Transterable anticancer innate immunity in spontaneous regression/complete resistance mice. Proc Natl Acad Sci USA 103: 7753-7758, 2006.

10. Cui Z, Willingham MC, Hicks AM, Alexandermiller MA, Howard TD, Hawkins GA, Miller MS, Weir HM, Du W and DeLong CJ: Spontaneous regression of advanced cancer: Identification of a unique genetically determined, age-dependent trait in mice. Proc Natl Acad Sci USA 100: 6682-6687, 2003.

11. Souto JC, Vila L and Brú A: Polymorphonuclear neutrophils and cancer: Intense and sustained neutrophilia as a treatment against solid tumors. Med Res Rev 31: 311-363, 2011.

12. Suttmann H, Riemensberger J, Bentien G, Schmaltz D, Stöckle M, Jocham D, Böhle A and Brandau S: Neutrophil granulocytes are required for effective bacillus Calmette-Guérin immunotherapy of bladder cancer and orchestrate local immune responses. Cancer Res 66: 8250-8257, 2006.

13. De Boer EC, De Jong WH, Steerenberg PA, Aarden LA, Tetteroo E, De Groot ER, Van der Meijden AP, Vegt PD, Debruyne FM and Ruitenberg EJ: Induction of urinary interleukin-1 (IL-1), IL-2, IL-6 and tumour necrosis factor during intravesical immunotherapy with bacillus Calmette-Guérin in superficial bladder cancer. Cancer Immunol Immunother 34: 306-312, 1992. 
14. de Boer EC, Somogyi L, de Ruiter GJ, de Reijke TM, Kurth KH and Schamhart DH: Role of interleukin-8 in onset of the immune response in intravesical BCG therapy for superficial bladder cancer. Urol Res 25: 31-34, 1997.

15. Monzavi-Karbassi B, Pashov A, Jousheghany F, Artaud C and Kieber-Emmons T: Evaluating strategies to enhance the anti-tumor immune response to a carbohydrate mimetic peptide vaccine. Int J Mol Med 17: 1045-1052, 2006.

16. Yoshie O, Aso H, Nanjo M, Tamura K, Ebina $\mathrm{T}$ and Ishida $\mathrm{N}$ : Antitumor effect of recombinant human interferon alpha A/D on Meth-A sarcoma in mice. Jpn J Cancer Res 77: 413-418, 1986.

17. Huntington ND, Vosshenrich CA and Di Santo JP: Developmental pathways that generate natural-killer-cell diversity in mice and humans. Nat Rev Immunol 7: 703-714, 2007.

18. Kim JM, Kim JS, Jung HC, Song IS and Kim CY: Apoptosis of human gastric epithelial cells via caspase-3 activation in response to Helicobacter pylori infection: Possible involvement of neutrophils through tumor necrosis factor alpha and soluble Fas ligands. Scand J Gastroenterol 35: 40-48, 2000.

19. Bisiaux A, Boussier J, Duffy D, Quintana-Murci L, Fontes M and Albert ML; Milieu Intérieur Consortium: Deconvolution of the response to bacillus Calmette-Guérin reveals NF- $\kappa \mathrm{B}$-induced cytokines as autocrine mediators of innate immunity. Front Immunol 8: 796, 2017

20. Queiroz DM, Guerra JB, Rocha GA, Rocha AM, Santos A, De Oliveira AG, Cabral MM, Nogueira AM and De Oliveira CA: IL1B and IL1RN polymorphic genes and Helicobacter pylori cagA strains decrease the risk of reflux esophagitis. Gastroenterology 127: 73-79, 2004.

21. Kayagaki N, Yamaguchi N, Nakayama M, Kawasaki A, Akiba H, Okumura K and Yagita H: Involvement of TNF-related apoptosis-inducing ligand in human CD4+ T cell-mediated cytotoxicity. J Immunol 162: 2639-2647, 1999.

22. Kayagaki N, Yamaguchi N, Nakayama M, Eto H, Okumura K and Yagita $\mathrm{H}$ : Type I interferons (IFNs) regulate tumor necrosis factor-related apoptosis-inducing ligand (TRAIL) expression on human t cells: A novel mechanism for the antitumor effects of type I IFNs. J Exp Med 189: 1451-1460, 1999.
23. Mariani SM and Krammer PH: Surface expression of TRAIL/Apo-2 ligand in activated mouse T and B cells. Eur J Immunol 28: 1492-1498, 1998.

24. Kashii Y, Giorda R, Herberman RB, Whiteside TL and Vujanovic NL: Constitutive expression and role of the TNF family ligands in apoptotic killing of tumor cells by human NK cells. J Immunol 163: 5358-5366, 1999.

25. Fanger NA, Maliszewski CR, Schooley K and Griffith TS: Human dendritic cells mediate cellular apoptosis via tumor necrosis factor-related apoptosis-inducing ligand (TRAIL). J Exp Med 190: 1155-1164, 1999.

26. Griffith TS, Wiley SR, Kubin MZ, Sedger LM, Maliszewski CR and Fanger NA: Monocyte-mediated tumoricidal activity via the tumor necrosis factor-related cytokine, TRAIL. J Exp Med 189: 1343-1354, 1999

27. Renshaw SA, Parmar JS, Singleton V, Rowe SJ, Dockrell DH, Dower SK, Bingle CD, Chilvers ER and Whyte MK: Acceleration of human neutrophil apoptosis by TRAIL. J Immunol 170: 1027-1033, 2003.

28. Ludwig AT, Moore JM, Luo Y, Chen X, Saltsgaver NA, O'Donnell MA and Griffith TS: Tumor necrosis factor-related apoptosis-inducing ligand: A novel mechanism for Bacillus Calmette-Guerin-induced antitumor activity. Cancer Res 64: 3386-3390, 2004.

29. Morales A, Eidinger D and Bruce AW: Intracavitary bacillus Calmette-Guerin in the treatment of superficial bladder tumors. J Urol 116: 180-183, 1976.

30. Kandoth C, McLellan MD, Vandin F, Ye K, Niu B, Lu C, Xie M, Zhang Q, McMichael JF, Wyczalkowski MA, et al: Mutational landscape and significance across 12 major cancer types. Nature 502: 333-339, 2013

31. Kusumanto YH, Dam WA, Hospers GA, Meijer C and Mulder NH: Platelets and granulocytes, in particular the neutrophils, form important compartments for circulating vascular endothelial growth factor. Angiogenesis 6: 283-287, 2003. 